\title{
Registro inédito de fósseis de vertebrados na Bacia Sedimentar de Curitiba (PR)
}

\author{
Antonio Liccardo ${ }^{1}$ \& Luiz Carlos Weinschütz ${ }^{2}$
}

\begin{abstract}
Resumo A Bacia Sedimentar de Curitiba, estudada há mais de 100 anos por vários autores tem sido descrita como essencialmente afossilífera. Os únicos registros até o momento eram estudos micropaleontológicos, que encontraram thecamoebianos, organófitos e restos vegetais micrométricos em argilitos das camadas superiores da Formação Guabirotuba e de bolsões de matéria orgânica com fibras vegetais e palinomorfos, também em meio ao argilito. Além destas rochas pelíticas, esta formação apresenta lentes e camadas localizadas de arcósios e areias arcosianas, muitas vezes com estratificação paralela ou cruzada. Recentemente, em meio a estes depósitos arenosos, foi registrada a ocorrência de dente e fragmentos de ossos na porção basal da Formação Guabirotuba. São fragmentos de ossos não identificados e um dente de crocodilomorfo zifodonte, provavelmente da subordem Mesosuchia. Esta é a primeira ocorrência de vestígios de vertebrados encontrados nesta bacia e suas informações poderão ser úteis na interpretação paleoambiental deste arcabouço. A ocupação urbana e a fragilidade destas rochas resultaram na existência de pouquíssimos afloramentos atualmente, o que torna a descoberta destes fósseis importante também no sentido de preservação legal do sítio.
\end{abstract}

Palavras-chave: Formação Guabirotuba, Bacia de Curitiba, fósseis vertebrados, crocodilomorfo, paleoclima.

\begin{abstract}
Vertebrate fossils record in Curitiba Sedimentary Basin, PR - Curitiba. Sedimentary Basin, which several authors have studied for more than a century, was described, essentially, as afossiliferous. The only registers until today are micropaleontological studies which met thecamoebians, organophyts and micrometric vegetal remains in claystones of the upper strata of Guabirotuba Formation, and some organic material with vegetal fibers and palinomorphs, also among the claystones. Beyond these pellitic rocks, this formation presents localized lens and layers of arcoses and arcosian sands, often with parallel or crossed stratification. Recently, among these deposits has been registered the occurrence of teeth and bone fragments in the basal portion of Guabirotuba Formation. They are unidentified bones and teeth of ziphodont crocodylomorpha, probably sub-order Mesosuchia. It's the first occurrence of vertebrates' signs found in this basin and its information could be useful to interpret the paleoclimate exchanges of this framework. Urban occupation and the fragility of these rocks result in the existence of few outcrops on the present time, that makes the discovery of these fossils important also for the legal preservation of the site.
\end{abstract}

Keywords: Guabirotuba Formation, Curitiba Basin, vertebrate fossils, crocodylomorpha, paleoclimate.

INTRODUÇÃO A Bacia Sedimentar de Curitiba, localizada no Primeiro Planalto Paranaense (Fig. 1) está entre as bacias terciárias brasileiras cujas rochas foram depositadas em condições paleoclimáticas muito específicas, que deixaram impressões características no conjunto litológico.

Estudada há mais de 100 anos por vários pesquisadores (e.g. Siemiradzki 1898; Maack 1947; Bigarella \& Salamuni 1962; Lopes 1966; Becker 1982; Salamuni 1998), esta bacia que aflora na maior parte do município de Curitiba e em parte da região metropolitana foi descrita como afossilífera. De fato, fósseis de grande porte não haviam sido encontrados até o momento, apenas foram registrados trabalhos de micropaleontologia de Azevedo (1981), que descreveu a presença de thecamoebianos, organófitos e restos vegetais micrométricos, encontrados nos argilitos das camadas superiores da Formação Guabirotuba e de menção de
Salamuni (1998) sobre ocorrência de bolsões de matéria orgânica com fibras vegetais e palinomorfos (pólens de angiospermas) em meio ao argilito.

Uma característica destes pacotes sedimentares é a pouca consolidação e consequente suscetibilidade dos afloramentos aos processos erosivos. Além disto, a alta taxa de ocupação do território curitibano levou à destruição ou recobrimento de grande parte dos afloramentos disponíveis, tornando inacessíveis os perfis clássicos descritos pelos autores mais antigos (e.g. Bigarella \& Salamuni 1959 ou Becker 1982).

A constatação de fragmentos de vertebrados encontrados fortuitamente num dos poucos afloramentos remanescentes desta bacia motivou a realização deste trabalho. $\mathrm{O}$ aprofundamento das pesquisas sobre este novo sítio paleontológico representa também uma fer- 


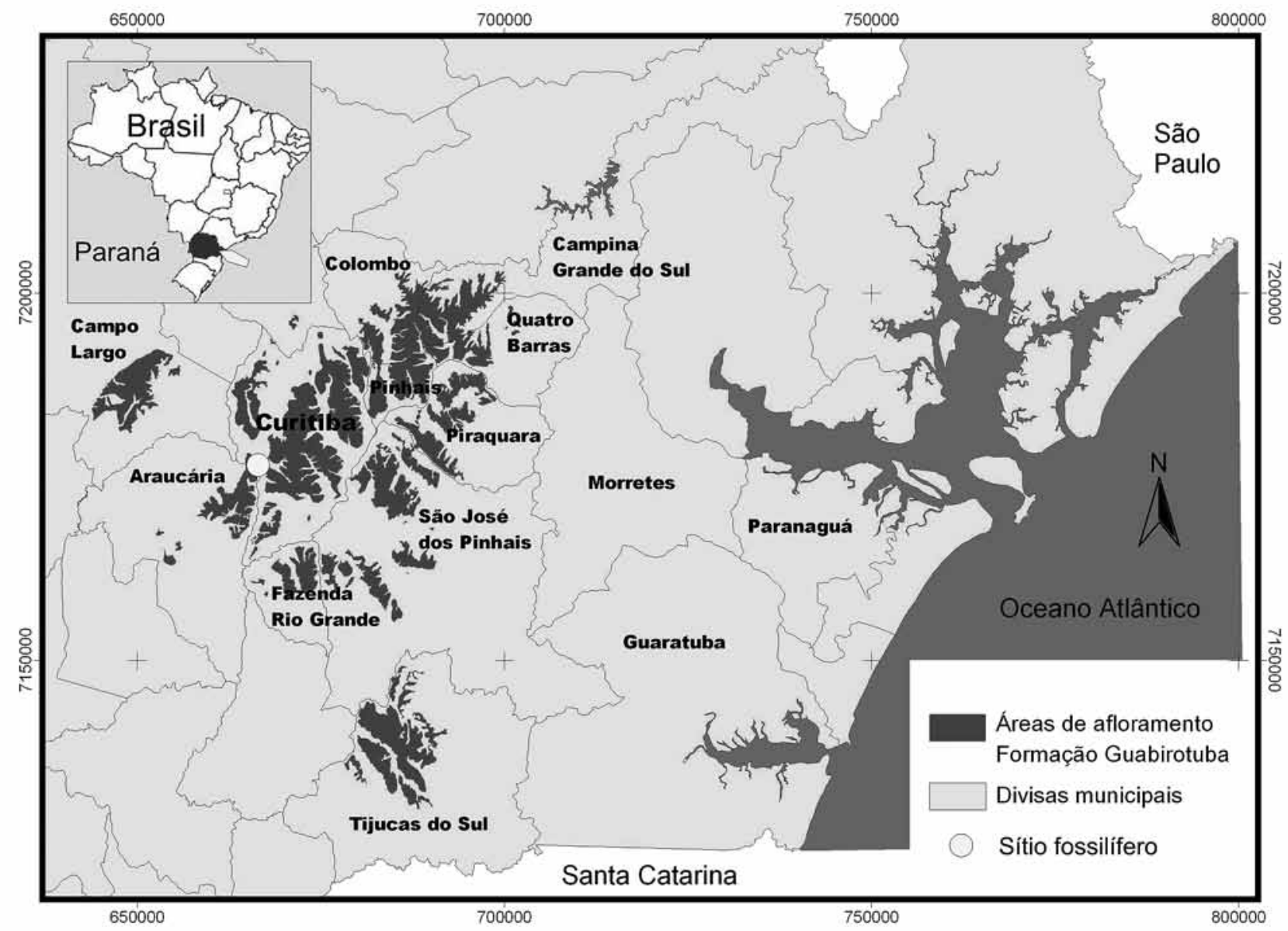

Figura 1 - Localização da parte aflorante da Bacia de Curitiba (Formação Guabirotuba) em relação ao município de Curitiba e parte da região metropolitana, localizados na porção leste do estado do Paraná (Primeiro Planalto Paranaense), ao sul do Brasil. Fonte: MINEROPAR

ramenta de embasamento teórico para a conservação legal deste patrimônio geológico e paleontológico, já que o afloramento recebeu indicações de preservação em projetos anteriores de geoturismo (Liccardo et al. 2008). Uma proposta de tombamento foi acordada com a Prefeitura de Curitiba por um dos autores (AL), baseada no valor científico e cultural deste contexto.

CONTEXTO GEOLÓGICO A Bacia Sedimentar de Curitiba aflora por cerca de $3.000 \mathrm{~km}^{2} \mathrm{e}$ é uma estrutura de pouca profundidade, com espessura média atual de $28 \mathrm{~m}$ e máxima de $81 \mathrm{~m}$ (Salamuni, 1998; Archela \& Yamamoto 2008a). Trata-se de uma depressão alongada de direção NNE-SSW, formada por rifteamento e preenchida por sedimentos a partir do Neógeno, no Cenozóico. Esta estrutura apóia-se sobre rochas metamórficas pré-cambrianas, como gnaisses-granitos e metabásicas, em parte migmatizados, e xistos magnesianos, as quais se encontram intensamente fraturadas, com falhas transcorrentes e normais, além de juntas de cisalhamento (Salamuni, 1998).

Os principais estudos sobre esta bacia foram realizados por Bigarella et al. (1961) que definiram o pacote de sedimentos cenozóicos como Formação Guabirotuba. Também nesta época Ab'Sáber \& Bigarella
(1961) e Bigarella \& Mousinho (1965) discutiram a geomorfologia e a formação de superfícies de relevo. Também Canali \& Muratori (1981) apresentaram uma síntese da evolução geomorfológica da bacia. Becker (1982) realizou o mais minucioso levantamento na região e subdividiu a estratigrafia em Formações Guabirotuba, Tingüis e Boqueirão, com base nas superfícies e características de erosão e deposição. Para esta autora a ausência de fósseis e camadas-guias levou a uma classificação baseada nos eventos paleoclimáticos cíclicos que se sucederam durante o Terciário e Quaternário. Esta subdivisão não é consensual e Salamuni (1998) sugere que formalmente apenas as formaçõs Guabirotuba e Tingüis poderiam ser aceitas.

A Formação Guabirotuba representa a maior parte destes sedimentos, com presença de argilitos, arcósios ou areias arcosianas, além de níveis conglomeráticos, na base da bacia. Eventualmente também estão presentes algumas cascalheiras com seixos de diversas naturezas e caliches ou calcretes (materiais carbonáticos ou camadas areno carbonáticas). Os arcósios ou arenitos feldspáticos, em geral se mostram como areias compactadas, mas pouco consolidadas, com até $60 \%$ de feldspato em sua composição. A presença destes arcósios é um forte indicativo de clima semi-árido na 
época da deposição. Outro sinal alusivo a essa interpretação é a presença esporádica de calcretes, crostas de grãos areno-siltosos cimentados por carbonato de cálcio, apontando ambientes quentes e secos. Ocasionalmente nestes sedimentos são encontrados cristais de Nd-lantanita, um raríssimo carbonato de terras raras, especialmente lantânio e neodímio, o que também suscita especulações paleoclimáticas em relação à gênese deste mineral.

A Formação Tingüis, conforme Becker (1982), é produto de retrabalhamento dos sedimentos da Formação Guabirotuba, com contato erosivo entre elas, também evidenciando uma mudança climática importante.

O preenchimento da Bacia de Curitiba por sedimentos se deu, provavelmente, num ambiente de vale amplo, largo, relativamente comprido e medianamente profundo, talvez com uns $100 \mathrm{~m}$ de profundidade. O clima era semi-árido, de chuvas torrenciais que ocorriam em longos intervalos de tempo, formando rios efêmeros com grande carga de sedimentos em direção ao vale, resultando em lagos turvos. Nas longas estiagens estes lagos secaram e os sedimentos preencheram o vale de forma lenta e gradual, depositando-se em camadas (Bigarella e Salamuni, 1961; Salamuni, 1998).

Os rios efêmeros que carrearam este material deixaram cascalho e areias para trás, formando cascalheiras na periferia e os argilitos no centro da Bacia de Curitiba. Este ciclo perdurou por alguns poucos milhões de anos, do Mioceno/Plioceno até o Pleistoceno. A fonte principal de sedimentos, apontada por Salamuni (1998), foram os contrafortes da Serra do Mar, que era mais alta e mais larga do que é hoje. Em suas encostas estavam depositados os produtos erodidos da própria montanha. Estudos recentes de procedência de minerais pesados (Machado, 2009) ratificaram esta idéia acrescentando uma contribuição das rochas metamórficas que hoje afloram ao norte de Curitiba. Análises em zircões indicaram múltiplas fontes, mas considerando análises de paleocorrentes e tendências de fluxo, as principais áreas-fonte dos sedimentos da Formação Guabirotuba foram a Província Graciosa, o Complexo Atuba e o Grupo Açungui. Salamuni (1998) estudou estruturalmente a bacia, propondo uma evolução tectônica do rift desde o Cretáceo, conforme ilustrado na figura 2.

Archela \& Yamamoto (2008b) apresentaram uma síntese a respeito da distribuição dessas rochas em quatro fácies sedimentares: a) orto e para-conglomerados polimíticos, referentes a porções proximais de leques aluviais; b) arenitos e lamitos conglomeráticos que equivalem às porções medianas dos leques; c) lamitos silto-argilosos homogêneos condizentes com porções distais dos leques; d) depósitos arenosos selecionados, com eventuais estratificações cruzadas, o que refletiria um retrabalhamento do grande aporte de material por águas de drenagem perenes em um sistema fluvial entrelaçado (braided). De maneira geral, para estes autores, esta distribuição faciológica na bacia sofreria uma variação lateral da borda para o centro segundo um modelo de leques aluviais proximais, sucedidos por leques aluviais médios, sucedidos por lamitos de fácies

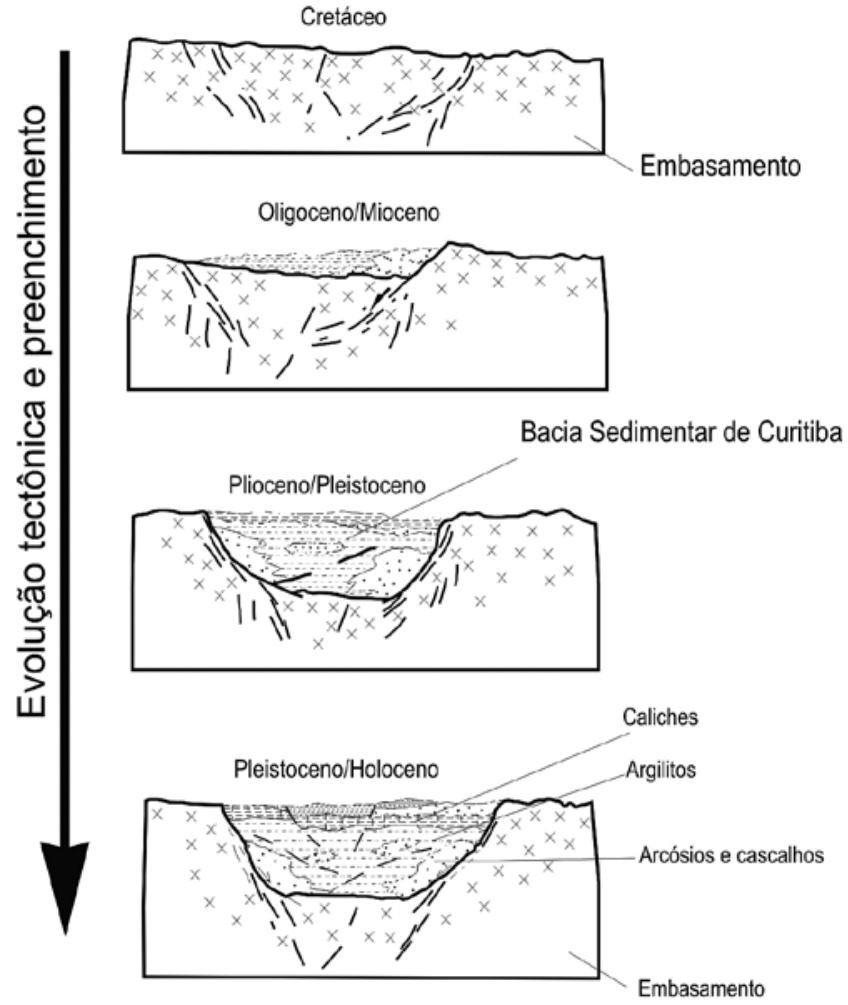

Figura 2 - Modelo simplificado em perfil da evolução da Bacia de Curitiba, que aponta o surgimento de falhas no período Cretáceo como início do abaixamento dos terrenos do embasamento para um posterior preenchimento sedimentar e diagênese do Oligoceno ao Pleistoceno (Salamuni, 1998).

distal e, finalmente, por uma fácies fluvial entrelaçada. Idéia semelhante já havia sido também aventada em trabalhos anteriores, como o de Salamuni et al. (2003).

Lima et al. (2008) realizaram estudos de campo, granulométricos, mineralógicos, petrográficos e de contexto tectônico regional que resultaram numa interpretação detalhada dos processos de deposição. Para estes autores foram identificados depósitos de leques aluviais proximais, com rudáceos polimíticos, associados a fluxos aquosos desconfinados, com feições de corte-e-preenchimento de canais com até $3 \mathrm{~m}$ de altura.

Em direção ao interior da bacia, este conjunto dá lugar a depósitos arenosos arcosianos, com estratificação cruzada e intercalações lenticulares e tabulares de diamictitos. Este contexto é indicativo de processos fluviais e gravitacionais coetâneos, que podem ser interpretados como porções intermediárias e distais dos leques aluviais. As partes centrais da bacia apresentam pacotes maiores de argilas maciças com intercalações arenosas, também com feições de corte-e-preenchimento de até $1 \mathrm{~m}$ de altura, o que corresponderia a lagos efêmeros. As crostas carbonáticas (caliches ou calcretes) têm sua origem atribuída a processos pedogenéticos em clima semi-árido.

A figura 3 apresenta um detalhamento geográfico e geológico do município de Curitiba, situando o afloramento onde se encontra o sítio fossilífero. 

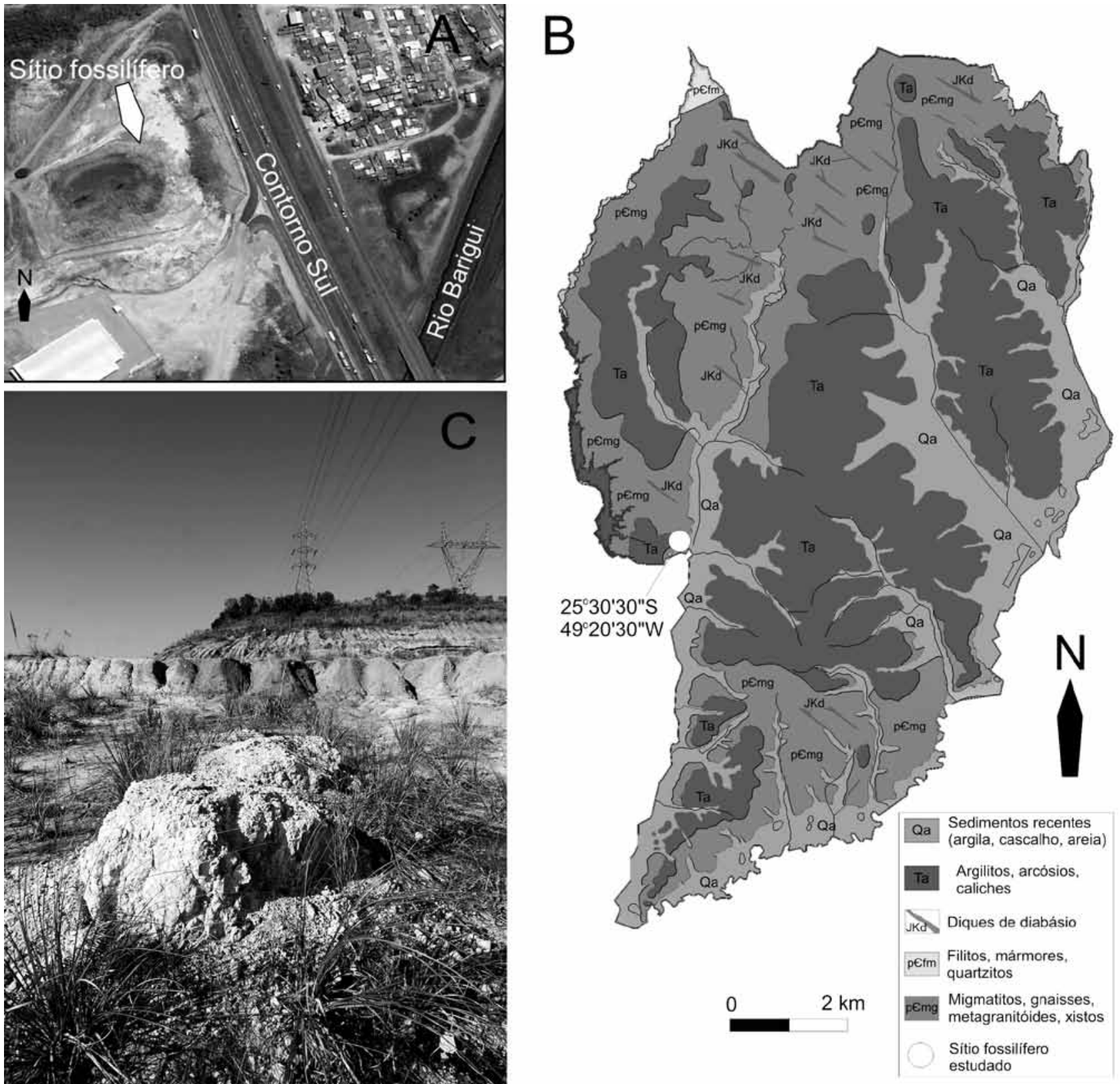

Figura 3 - A - Imagem aérea e situação do afloramento à margem do Contorno Sul (Fonte: Google Earth); $B$ - Mapa geológico simplificado com principais drenagens do municipio de Curitiba, onde aflora boa parte da bacia sedimentar (Ta) e onde se localiza o sítio fossilifero descoberto (modificado de Liccardo et al. 2008); $C$-Imagem da face norte do afloramento, com as torres de alta tensão visíveis no topo e sedimentos carbonáticos (caliche) em primeiro plano.

DESCRIÇÃO DO AFLORAMENTO As rochas sedimentares da bacia de Curitiba são pouco consolidadas e relativamente frágeis quando expostas ao intemperismo e erosão. $\mathrm{O}$ avanço da zona urbana com intensa impermeabilização (calçadas, asfalto, cimento...) levou ao virtual desaparecimento da maior parte dos afloramentos. O que era facilmente observável em uma grande parte da cidade há 30 ou 50 anos atualmente tornou-se difícil e poucos locais restaram tão didáticos para a compreensão da bacia sedimentar, quanto este afloramento onde foram encontrados os fósseis. No levantamento geoturístico do município de Curitiba, Lic- cardo et al. (2008) propuseram este afloramento como uma didática seção-tipo da bacia, com recomendações de sua preservação em função do valor cultural geológico, ligado principalmente à estratigrafia.

$\mathrm{O}$ local encontra-se à margem do Contorno Sul anel rodoviário que contorna a cidade - no bairro Cidade Industrial (CIC), limite sudoeste do município de Curitiba na divisa com Araucária e a poucos metros do rio Barigüi

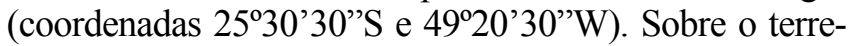
no encontra-se uma linha de transmissão de energia (alta tensão) com torres de grande porte, o que de certo modo contribuiu para a proteção do afloramento em relação a 
alterações antrópicas, ao contrário dos arredores que se encontram bastante modificados pela ação humana.

Além de apresentar exposições de caliche, arcósios, argilitos, níveis conglomeráticos e solo típicos das formações descritas, este afloramento exibe contatos geológicos facilmente identificáveis entre os xistos e gnaisses alterados do embasamento e a bacia, ou mesmo entre os estratos, além de importantes estruturas sedimentares, observáveis ao longo de um perfil com cerca de 15 metros de altura.

Eventualmente são encontrados depósitos de seixos e areia mais grossa na base dos pacotes de rochas sedimentares, que normalmente são associados a um ambiente de enxurrada compatíveis com clima semi-desértico, predominante na época da deposição. A presença de arcósios em meio aos argilitos na forma de lentes em estratos horizontais é facilmente observável nas faces oeste e norte, graças a diferentes resistências ao desgaste. Enquanto os argilitos se decompõem facilmente, os arcósios resistem melhor à erosão, permanecendo muitas vezes quase suspensos.

No corte em discussão se observa a seguinte distribuição litotípica, conforme apresentado na figura 4 a partir da base encontram-se xistos com veios de quartzo estirado de espessuras milimétricas a centimétricas e gnaisses alterados, correspondentes ao embasamento (Complexo Atuba). Em sobreposição está disposta uma camada de argilito com eventuais grãos decimétricos

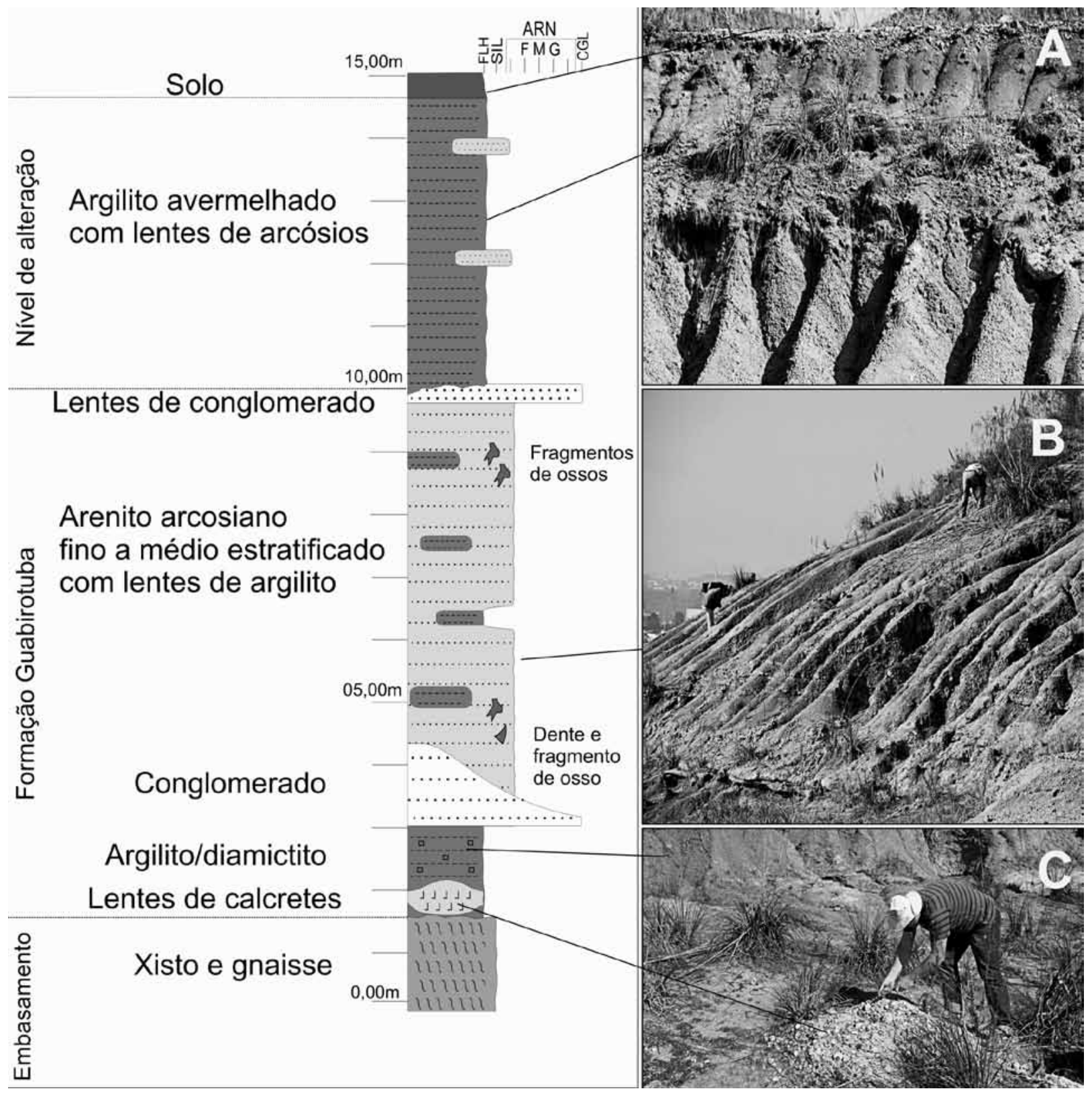

Figura 4 - Estratigrafia verificada no sitio fossilifero com indicação do nível onde foram encontrados os fragmentos e imagens correspondentes aos estratos observados. A-Parte superior dos sedimentos, com nítidos sinais de alteração. B-Nivel fossilifero composto predominantemente por arenitos arcosianos. C-Ocorrência de lente de calcrete. 
de composição variada, de coloração cinza esverdeada, com cerca de $1,5 \mathrm{~m}$ de espessura e intercalações métricas de calcretes. O contato destes sedimentos com o embasamento é erosivo.

Sobre estes diamictitos encontra-se um pacote de sedimentos variados com uma espessura média de $7 \mathrm{~m}$, com predominância de arenito arcosiano fino a médio que apresenta estratificação plano-paralela. $\mathrm{Na}$ base e no topo deste pacote os grãos tendem a ser mais grosseiros formando lentes e níveis conglomeráticos. Intercalados em todo o pacote encontram-se lentes de material mais fino (argilito) de dimensões centimétricas. Neste nível foram encontrados os fósseis, sendo o dente e um fragmento de osso em porção mais basal e outros dois fragmentos ósseos encontrados mais próximo ao topo. Os sedimentos, a partir do contato com o xisto, constituem a Formação Guabirotuba.

Sobrepondo-se a este nível mais grosseiro dispõe-se um pacote de cerca de $5 \mathrm{~m}$ de argilito avermelhado com um ravinamento característico e empastilhamento das argilas superficiais (formado por retração e expansão de illitas e montmorilonitas). Neste nível encontram-se pequenas lentes arcosianas. No topo do perfil existe a formação de solo com cerca de $30 \mathrm{a} 40 \mathrm{~cm}$ de espessura com vegetação predominante de gramíneas.

OS FÓSSEIS Foram coletados um dente e três fragmentos ósseos, sendo neste estudo enfatizada a descrição do dente em função de seu estado satisfatório de conservação. Os fragmentos ósseos são descritos sumariamente, caracterizando a presença de vertebrados na Bacia Sedimentar de Curitiba, mas dependem de estudos mais aprofundados e novas coletas para a possível definição da espécie, ou se pertencem ou não a crocodilomorfos.

Como indicado no perfil representado na figura 4 , o dente e um dos fragmentos de osso foram encontrados próximo a base de um espesso pacote $(6$ a $7 \mathrm{~m})$ de arenito arcosiano fino a médio, pertencente a Formação Guabirotuba, e outros dois fragmentos ósseos mais próximos ao topo deste litotipo. A distribuição destes fósseis na base e no topo do arenito arcosiano sugere a possibilidade de ocorrência fossilífera em todo o pacote sedimentar, com potencial para novos achados neste afloramento, principalmente no nível arcosiano.

Os fragmentos ósseos são constituídos de três peças aparentemente independentes e de difícil diagnóstico, onde em cada uma delas está exposta parte da porção externa e parte da porção interna do osso. Uma das peças apresenta forma achatada com comprimento de $38 \mathrm{~mm}$ e largura de $28 \mathrm{~mm}$ (Fig. 5-A); a menor apresenta forma aproximadamente arredondada com comprimento maior de $37 \mathrm{~mm}$ e largura máxima de $25 \mathrm{~mm}$ (Fig. 5 -B); a peça de maior dimensão apresenta comprimento de $63 \mathrm{~mm}$ e largura máxima de $33 \mathrm{~mm}$ (Fig. 5-C).

O dente encontrado é do tipo zifodonte, ou seja, apresenta-se comprimido no sentido lateral, com ausência da porção apical, apresentando $35 \mathrm{~mm}$ de comprimento, com $23 \mathrm{~mm}$ na maior largura da base e $14 \mathrm{~mm}$ na menor largura da base (Fig. 6). Os bordos anterior e posterior são serrilhados (Fig. 7-A,B) e observa-se também a presença
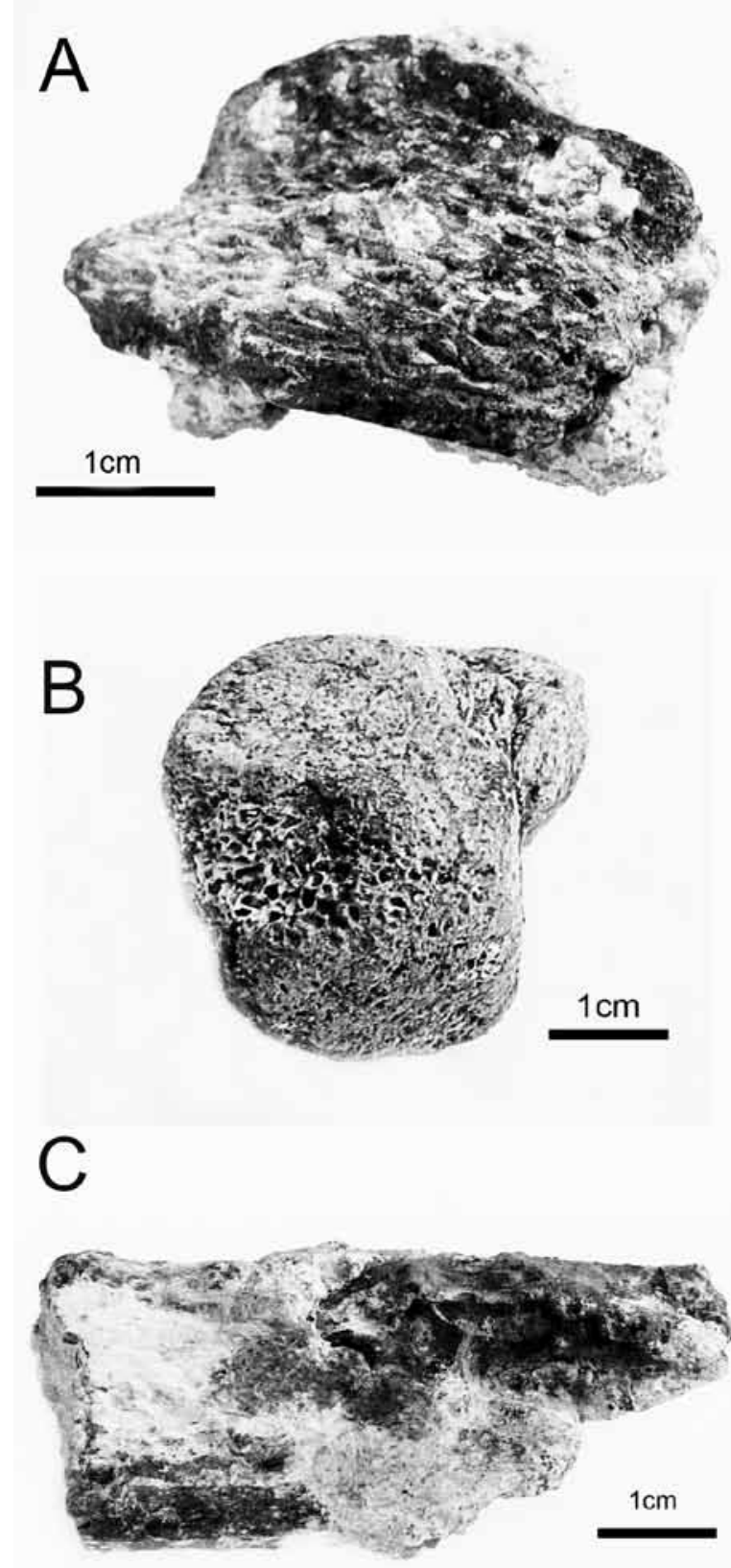

Figura 5 - Imagens dos fragmentos de ossos encontrados. Em A e C observa-se a presença de sedimentos fortemente aderidos, principalmente com composição caulinítica. O fragmento $B$ é constituído exclusivamente de restos ósseos, sem sedimentos aderidos.

de estrias longitudinais não maiores que $0,5 \mathrm{~mm}$ em toda a extensão da peça (Fig. 7-C). O dente teria comprimento total em torno de $45 \mathrm{~mm}$, o que o caracterizaria como pertencente a um crocodilomorfo de grande porte.

Dentro da Ordem Crocodylomorpha, a Subordem Mesosuchia engloba crocodilomorfos continentais terrestres, que possuíam dentes semelhantes aos teropodomorfos, ou seja, deprimidos lateralmente e com bordos serrilhados (Bertini, 2000). Dentro desta Subordem, a família Sebecidae, com ocorrência no Brasil (Bacia de Itaboraí, gênero Sebecus, Paleoceno) apre- 

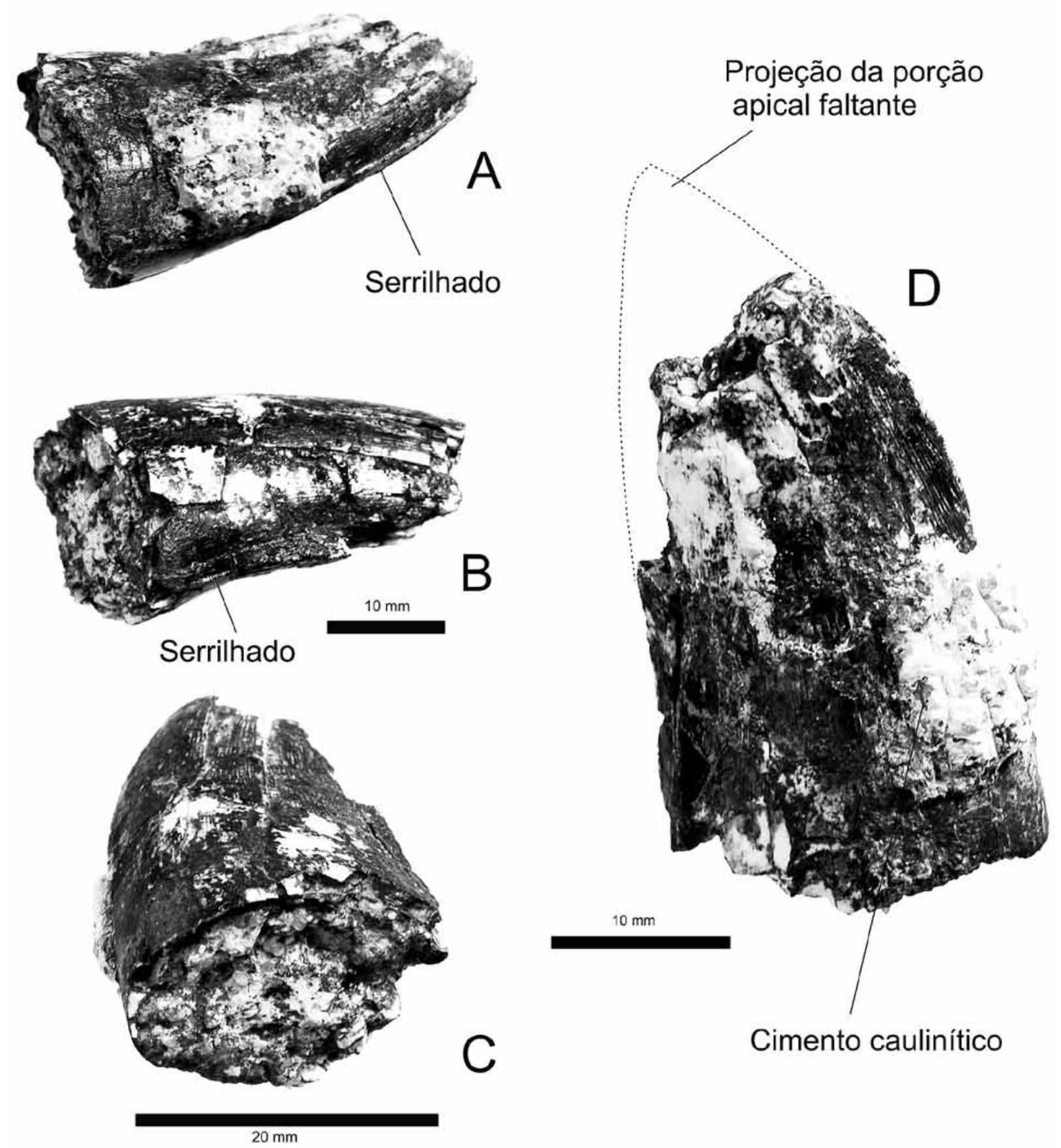

Cimento caulinítico

Figura 6 - Dente tipo zifodonte, onde se observa parte anterior (A) e posterior (B) serrilhadas; o achatamento lateral (C) e a estimativa do comprimento total e diâmetro maior da base (D).
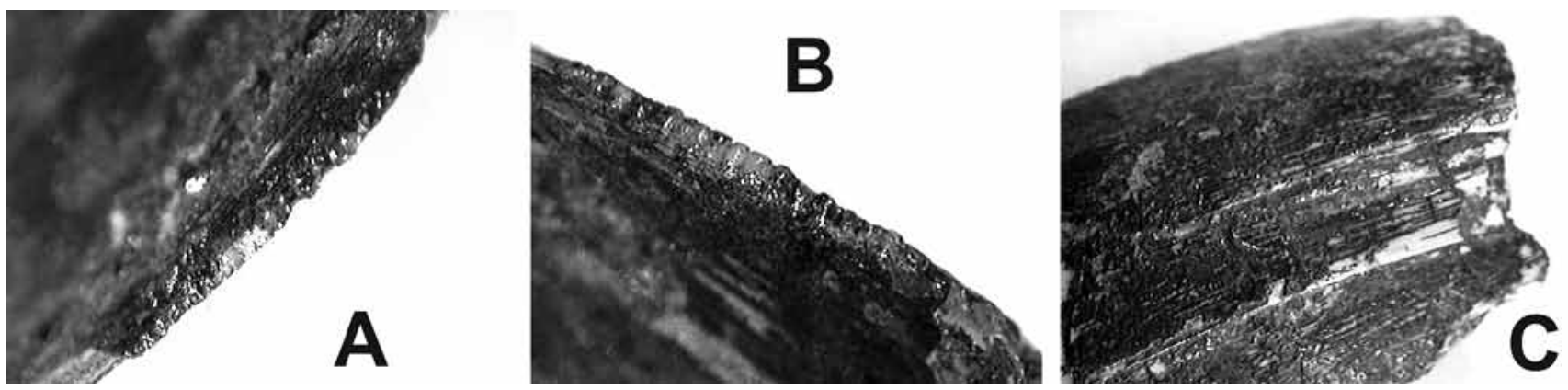

Figura 7 - Detalhes do serrilhamento anterior (A) e posterior (B), e das estrias longitudinais $(C)$ no dente. 
senta possível correspondência cronológica (Paleoceno Médio a Pleistoceno Superior) aos fósseis encontrados.

DISCUSSÃO A presença de fósseis de vertebrados na Bacia Sedimentar de Curitiba, considerada até então praticamente afossilífera, apresenta novas perspectivas para sua interpretação paleoambiental. Muitas considerações a respeito dos paleoclimas predominantes na deposição da Bacia de Curitiba já foram tecidas, fundamentadas nos estudos dos sedimentos e seus modos deposicionais. Remanescentes de pediplanos e pedimentos permitiram a Bigarella et al. (1961) e Becker (1982) concluirem sobre as alternâncias climáticas e sobre a natureza poligenética das formas de relevo. Superfícies planas desenvolveram-se durante semi-aridez e as formas dissecadas em episódios de umidade, conforme os detalhados estudos de Becker (1982). Esta autora definiu a estratigrafia com base nas superfícies de relevo, subdividindo os sedimentos em Formações Guabirotuba, Tingüis e Boqueirão.

As variações climáticas foram cíclicas, predominando processos de degradação lateral durante o clima semi-árido e a dissecação vertical durante climas úmidos. A alternância climática exerceu profunda influência nas condições hidrológicas que afetaram os processos hidrodinâmicos e morfodinâmicos. Movimentos de massa foram característicos nas transições de clima úmido para semi-árido, contribuindo para a deposição nas depressões constituídas por alvéolos ou compartimentos maiores (Becker 1982).

Alguns grupos de crocodilomorfos apresentavam características adaptativas para sobrevivência em ambientes terrestres semi-áridos, principalmente os pertencentes à Subordem Mesosuchia. Na região do oeste paulista, existiu um grupo de crocodilomorfos - os Baurusuchidae - muito diferente dos crocodilos atuais. Eram animais adaptados ao clima quente e seco, em que as chuvas eram raras. Podiam viver afastados dos corpos d'água e eram capazes de percorrer longas distâncias. Campos et al. (2005) e Carvalho et al. (2005) estudaram esqueletos completos de baurusuquídeos (encontrados na Bacia de Bauru, em São Paulo) e sugeriram que eles estavam habilitados a escavar no substrato, produzindo estruturas de escavação como estratégia de termo regulação, o que possibilitava que estes crocodilomorfos tivessem uma boa adaptação aos ambientes quentes e áridos. Já os crocodilomorfos de família Sebecidae eram predadores continentais caracterizados por crânios altos e lateralmente comprimidos, providos de dentes serrilhados e em número reduzido. No estado do Rio de Janeiro, na Bacia de Itaboraí, foi registrado o gênero Sebecus (Buffe-Taut, 1979 in Bertini, 2000) em sedimentos do Paleoceno Médio.

Outro exemplo de descoberta mais recente em paleoambiente árido foi a do Armadillosuchus arrudai (Marinho \& Carvalho 2009), conhecido como "crocodilo-tatu", também na região oeste de São Paulo. Este animal, único no mundo, apresentava condições de adaptação desconhecidas em crocodilos atuais, como a capacidade de escavar e se enterrar, à semelhança de tatus, e longas presas posteriores, semelhantes aos queixadas.

Nos crocodilos atuais a sua distribuição é controlada por uma temperatura média igual ou superior a $14,2^{\circ} \mathrm{C}$, e as condições hidrológicas também têm um papel importante, funcionando como um controlador das temperaturas extremas. Os fósseis em questão foram encontrados em sedimentos que indicam um ambiente árido a semi-árido, situação similar àquela dos crocodilomorfos Baurusuchidae, cujas ocorrências sugeriram adequação aos ambientes terrestres e áridos. $\mathrm{O}$ Baurusuchus salgadoenses vivia em área de alternância climática, sendo adaptado a um ambiente quente e seco. Quando passava muito tempo sem água enterrava-se para evitar a desidratação (Campos et al. 2005).

Os crocodilomorfos foram predadores carnívoros, que possivelmente caçavam em bando, podiam alcançar $3 \mathrm{~m}$ de comprimento e pesar cerca de $400 \mathrm{~kg}$. As patas alongadas do animal mostram que se locomovia por grandes distâncias, o que foi comprovado pelo estudo de outros baurusuquídeos na Argentina e no Paquistão (Carvalho et al. 2005). Estes répteis viveram há cerca de 90 milhões de anos. Os fósseis foram encontrados em uma sucessão de arenitos maciços finos, com geometria tabular, intensamente bioturbados. A seqüência é interpretada como a planície de inundação de rios entrelaçados em um clima quente e árido (Campos et al. 2005).

Embora o dente em questão esteja quebrado no ápice, este não apresenta sinais de grande desgaste, tendo sua deposição acontecido em fluxos de água e sedimentos originados por tormentas esporádicas. Sua origem por retrabalhamento é pouco provável, ou seja, o fóssil é contemporâneo à deposição dos sedimentos, ainda que sua presença isolada evidencie que o mesmo foi transportado.

Estratigraficamente os fósseis estão inseridos em um pacote de arenitos arcosianos pertencentes à Formação Guabirotuba, unidade inferior da Bacia Sedimentar de Curitiba, com deposição ocorrida entre o intervalo Mioceno/Plioceno - Pleistoceno. Este período não é compatível com a presença dos baurusuquídeos, que seriam mais antigos, ou mesmo com o $A r-$ madillosuchus arrudai. Neste contexto sugere-se que o dente encontrado seja pertencente a um crocodilomorfo da Subordem Mesosuchia, família Sebecidae, cuja distribuição temporal corresponde ao intervalo Paleoceno Médio - Pleistoceno Superior, o que seria condizente com as idades dos sedimentos da bacia apregoadas pela maioria dos autores.

CONSIDERAÇÕES FINAIS A descoberta desses fragmentos fósseis na Bacia de Curitiba se apresenta como uma potencial ferramenta de auxílio na interpretação crono-estratigráfica. Os fragmentos ósseos revelam por si só a existência de vertebrados de grande porte num ambiente tido como desfavorável até então. As recentes descobertas em outros locais, de crocodilomorfos resistentes a ambientes áridos, conduzem a um refinamento na compreensão paleoclimática e deposicional proposta pelos vários autores que estudaram esta bacia.

Apesar do amplo espectro temporal de existência dos crocodilomorfos, dificultando uma inferência clara de 
idade que pudesse ser aplicada imediatamente aos sedimentos coetâneos, o fragmento de dente encontrado poderá elucidar vários pontos pouco compreendidos na deposição desses sedimentos. Também o potencial fossilífero deste afloramento deverá ser mais intensamente investigado, o que poderá acarretar em importantes avanços no estudo estratigráfico das bacias terciárias brasileiras.

$\mathrm{O}$ registro do primeiro sítio fossilífero no município de Curitiba num momento em que se discute a preservação do patrimônio geológico é de grande importância para o tombamento formal deste afloramento. Localizado em pleno núcleo urbano, este sítio geológico-paleontológico pode significar um vínculo entre o patrimônio geológico e o patrimônio cultural do município, valorizando a importância científica da descoberta. Ainda, com o objetivo de disponibilização máxima da informação e do interesse geoturístico, os fósseis encontrados foram tombados no Museu da Terra e da Vida (CENPALEO), em Mafra (SC), sob os números CP/E 5856 (dente), CP/E 5857 (fragmento A), CP/E 5858 (fragmento B) e CP/E 5859 (fragmento C).

Agradecimentos Os autores manifestam o seu reconhecimento e agradecimento aos alunos do curso de Geografia da UFPR, que participaram do achado dos primeiros fragmentos, em especial a Felipe Tod. Também aos colegas Cristina Silveira Vega, Gilson Burigo Guimarães e Eduardo Salamuni, pelas profícuas discussões, leituras e sugestões.

\section{Referências}

Ab'Saber A.N. \& Bigarella J.J. 1961. Superfícies aplainadas do primeiro planalto do Paraná. Boletim Paranaense de Geografia, 4-5:116-125.

Archela E. \& Yamamoto J.K. 2008(a). Identificação e Tendência na Distribuição das Fácies Sedimentares Presentes na Bacia de Curitiba - PR. In: SBG, Congresso Brasileiro de Geologia, 44, Curitiba, Anais, p.121.

Archela E. \& Yamamoto J.K. 2008(b). Modelagem de Paleorelevo do Embasamento da Bacia Sedimentar de Curitiba - PR. In: SBG, Congresso Brasileiro de Geologia, 44, Curitiba, Anais, p. 125

Azevedo F.F. 1981. Camoebianos e organófitos na Formação Guabirotuba. In: SBG, Simpósio Regional de Geologia, 3, Curitiba, Atas, 2:226-242.

Becker R.D. 1982. Distribuição dos sedimentos cenozóicos na Região Metropolitana de Curitiba e sua relação com a estrutura geológica e morfológica regional. Tese PósGraduação em Geociências, UFRGS.

Bertini R.J. 2000. Répteis. In: Carvalho I. de S. (org.) Paleontologia. 1 ed., Rio de Janeiro: Interciência, v. 1, p. 543-577.

Bigarella J.J. \& Mousinho M.R. 1965. Significado paleogeografico e paleoclimático dos depósitos rudáceos. Boletim Paranaense de Geografia, 16-17:7-41.

Bigarella J.J. \& Salamuni R. 1959. Notas complementares à planta geológica da cidade de Curitiba e arredores. Boletim do Instituto de Biologia e Pesquisas Tecnológicas, Curitiba, n. 40.

Bigarella J.J. \& Salamuni R. 1962. Caracteres texturais dos sedimentos da Bacia de Curitiba (contribuição à geologia geral). Boletim da Universidade Federal do Paraná, Geologia, Curitiba, 7:1-164.

Bigarella J.J., Salamuni R., Ab’sáber A.N. 1961. Origem e ambiente de deposição da Bacia de Curitiba. Boletim Paranaense de Geociências, 4-5:71-81.

Campos A.C.R., Carvalho I.S., Arruda J.T., Nobre P.H., Tavares S.A.S. 2005. Significado paleoambiental e paleoclimático de Baurusuchus salgadoensis (Crocodylomorpha, Cretáceo Superior) da Bacia Bauru. In: SBH, Congresso Brasileiro de Herpetologia, 2, Belo HorizonteMG, Anais, Pdf 861.

Canali N.E. \& Muratori A.M. 1981. Síntese da evolução ge- omorfológica da Bacia Sedimentar de Curitiba. In: SBGSP, Simpósio Regional de Geologia, 3, Curitiba, Atas, 2:363-371.

Carvalho I.S., Campos A.C.A., Nobre P.H. 2005. Baurusuchus salgadoensis, a New Crocodylomorpha from the Bauru Basin (Cretaceous), Brazil.Gondwana Research, 8(1):11-30.

Liccardo A., Piekarz G. F., Salamuni E. 2008. Geoturismo em Curitiba. Curitiba, Ed. Mineropar, 122 p.

Lima F.M., Fernandes L.A., Melo M.S. Guimarães G.B., Goes A., Machado D.A.M., Lemos J., Perico E., Melo T.F.S. 2008. Preenchimento Sedimentar da Bacia de Curitiba - PR. In: SBG, Congresso Brasileiro de Geologia, 44, Curitiba, Anais, p.129

Lopes J.A.U. 1966. Nota explicativa da folha geológica de Curitiba. Boletim da Universidade Federal do Paraná. Geologia, Curitiba, n. 20.

Maack R. 1947. Breves notícias sobre a geologia dos estados do Paraná e de Santa Catarina. Arquivos de Biologia e Tecnologia, Curitiba, 2:63-154.

Machado D.A.M. 2009. Proveniencia de sedimentos da Bacia de Curitiba por estudo de minerais pesados. Dissertação de Mestrado, Universidade Federal do Paraná, Curitiba.

Marinho T.S. \& Carvalho I.S. 2009. An armadillo-like sphagesaurid crocodyliform from the Late Cretaceous of Brazil. Journal of South American Earth Sciences, 27(1):36-41

Salamuni E. 1998. Tectônica da Bacia Sedimentar de Curiti$b a(P R)$. Tese de Doutoramento, Universidade Estadual Paulista, Rio Claro, 210 p.

Salamuni E., Ebert H.D., Borges M. da S., Hasui Y., Costa J.B.S., Salamuni R. 2003. Tectonics and sedimentation in the Curitiba Basin, south of Brazil. Journal of South American Earth Sciences, Oxford, 15(8):901-910.

Siemiradzki J. 1898. Geologische Reisebeobachtungen in Sudbrasilien. Sitzungsberichte der Heidelberger Akademie der Wissenschaften, Mathematisch-Naturwissenschaftliche Klasse, Heidelberg, B. CVII, Abt. I, p. 23-39.

Manuscrito ID 14971

Submetido em 09 de agosto de 2009 Aceito em 15 de junho de 2010 